IZA DP No. 5271

Neighbourhood Effects, Housing Tenure, and Individual Employment Outcomes

David Manley

Maarten van Ham

October 2010 


\title{
Neighbourhood Effects, Housing Tenure, and Individual Employment Outcomes
}

\author{
David Manley \\ University of St Andrews
}

Maarten van Ham

University of St Andrews

and IZA

\section{Discussion Paper No. 5271 \\ October 2010}

\author{
IZA \\ P.O. Box 7240 \\ 53072 Bonn \\ Germany \\ Phone: +49-228-3894-0 \\ Fax: +49-228-3894-180 \\ E-mail: iza@iza.org
}

Any opinions expressed here are those of the author(s) and not those of IZA. Research published in this series may include views on policy, but the institute itself takes no institutional policy positions.

The Institute for the Study of Labor (IZA) in Bonn is a local and virtual international research center and a place of communication between science, politics and business. IZA is an independent nonprofit organization supported by Deutsche Post Foundation. The center is associated with the University of Bonn and offers a stimulating research environment through its international network, workshops and conferences, data service, project support, research visits and doctoral program. IZA engages in (i) original and internationally competitive research in all fields of labor economics, (ii) development of policy concepts, and (iii) dissemination of research results and concepts to the interested public.

IZA Discussion Papers often represent preliminary work and are circulated to encourage discussion. Citation of such a paper should account for its provisional character. A revised version may be available directly from the author. 


\section{ABSTRACT \\ Neighbourhood Effects, Housing Tenure, and Individual Employment Outcomes}

This paper investigates whether individuals living in neighbourhoods with high concentrations of unemployment are less likely to enter work if they are unemployed and more likely to lose their job if they are employed. The main challenge in the neighbourhood effects literature is the identification of causal neighbourhood effects. A particular problem is that individuals do not randomly select neighbourhoods to live in: the selection process is often linked to the labour market situation and potential of individuals. To get more insight in neighbourhood effects we run separate models for social renters and owner occupiers. This study uses anonymised individual level longitudinal data from the Scottish Longitudinal Study for 1991 and 2001 with multiple neighbourhood scales operationalised. Based on the results we argue that any apparent neighbourhoods effects that were present in models of the full population are at least partly an artefact of different neighbourhood selection mechanisms. The conclusions of the paper call for a more nuanced treatment of neighbourhood effects and the development of models that seek to include neighbourhood selection from the outset.

JEL Classification: $\quad$ I30, J60, R23

Keywords: neighbourhood deprivation, neighbourhood effects, labour market outcomes, longitudinal data, Scotland

Corresponding author:

David Manley

Centre of Housing Research

School of Geography \& Geosciences

University of St Andrews

Irvine Building, North Street

KY16 9AL St Andrews, Fife

United Kingdom

E-mail: d.manley@st-andrews.ac.uk

\footnotetext{
* Chapter prepared for the forthcoming book Neighbourhood Effects Research: New Perspectives, edited by Van Ham M., Manley D., Bailey N., Simpson L., Maclennan D (Chapter 7). Springer Dordrecht (http://www.springer.com/).
} 


\section{Introduction}

Many academics and policy makers believe in neighbourhood effects: the idea that living in a poor neighbourhood can severely reduce an individual's life chances with respect to their health outcomes, educational achievement and labour market performance (for an overview of the literature see Ellen and Turner, 1997; Dietz, 2002; Galster, 2011). The literature suggests a wide range of theoretical pathways by which the neighbourhood context can influence individual outcomes (see Durlauf, 2004). These pathways include a lack of positive role models, negative socialisation, a physical disconnection from job-finding networks, a culture of dysfunctional values and disconnection from mainstream society, discrimination by institutions and employers from outside the neighbourhood, access to low quality public services, and an exposure to high levels of criminal behaviour.

There is a large body of qualitative and quantitative research showing evidence of negative neighbourhood effects of living in deprived neighbourhoods. Qualitative research has contributed greatly to the development of theory and hypotheses and has mostly found evidence in favour of the neighbourhood effects hypothesis. But by its very nature, qualitative research does not produce generalisable outcomes as very specific cases are studied. The body of quantitative studies is inconclusive with regard to the question whether neighbourhood effects exist, and if they do, which of the causal pathways are the most important. Much of the quantitative work has been criticised for failing to address a series of econometric problems - most importantly selection bias - related to the identification of causal relationships (Durlauf, 2004; Cheshire, 2007; Van Ham and Manley, 2010).

There is no doubt that neighbourhood poverty and individual disadvantage are strongly correlated, but it is much less certain that there is a causal relationship between the two. The main challenge in the study of neighbourhood effects is identifying causal pathways, directly relating neighbourhood context to individual outcomes (Cheshire, 2011). It has been argued that the apparent relationship between the neighbourhood context and individual outcomes may not be causal, and might merely be a reflection of the ability of different groups in society to select a good neighbourhood in which to live (Van Ham \& Manley, 2010; and see the chapter by Bergström and van Ham, 2011 in this volume). It is highly problematic to identify causal neighbourhood effects while using observational data (Durlauf, 2004) as in such data households are normally not allocated to neighbourhoods randomly. Even in (quasi) experimental data, for instance from the Gautreaux Project in Chicago or the wider Moving To Opportunity Programs (Rosenbaum, 1995; Katz et al., 2001; Ludwig et al., 2001; Goering et al., 2002) allocation to neighbourhoods is not completely random. Studies using observational and experimental data reach conflicting conclusions, with some studies positively identifying neighbourhood effects, while other report no (causal) effects. The question whether the effects found are selection effects or causal effects is highly relevant in the context of formulating policy responses to concentrations of poverty and associated problems.

This chapter aims to give more insight into the potential effects of selection bias on estimates of neighbourhood effects. The chapter builds on studies by Oreopoulos (2003) and van Ham and Manley (2010) which analysed neighbourhood effects separately for social renters and homeowners. The idea behind separate models for different housing tenures is that social renters have less freedom to choose a neighbourhood than homeowners. Social renters are generally allocated a dwelling in a neighbourhood and although the allocation mechanism is not completely random, it approximates an experimental setting. Homeowners choose their dwelling and neighbourhood based on preferences, resources (income and ability to get a mortgage) and what is available in the market. The more resources a household can 
use for housing, the larger the choice set. If tenure split models find correlations between neighbourhood characteristics and individual outcomes for social renters, these are likely to be real causal neighbourhood effects as their individual characteristics are unlikely to have played a large role in the allocation of a dwelling in a particular neighbourhood by a housing officer.

In this chapter we explore the tenure split approach by testing the hypothesis that living in a neighbourhood with high levels of unemployment has a negative effect on individual labour market outcomes. Based on the theoretical literature it can be expected that those living in neighbourhoods with high levels of unemployment are less likely to be in contact with positive role models, are more likely to have unemployed friends and neighbours which might cause negative socialisation, are less likely to know people who can help finding a job, and are more likely to be stigmatised by outsiders. This study will investigate the following two questions: To what extent does living in a neighbourhood with a high level of unemployment reduce an individual's chances of having work in 2001 if they were unemployed in 1991?; To what extent does living in a neighbourhood with a high level of unemployment reduce an individual's chances of having work in 2001 if they were employed in 1991? We used unique data from the Scottish Longitudinal Study (SLS) which is a 5.3\% anonymised sample of the Scottish population linked through time by matching census records from 1991 and 2001. Using this data, we are able to link 1991 neighbourhood characteristics to 2001 labour market outcomes. The data is not without limitations, but it is one of the best longitudinal datasets available to study neighbourhood effects.

\section{Background}

\section{Theoretical considerations}

There is a large and growing literature investigating how the neighbourhood context can influence individual life chances (see for literature reviews Ellen and Turner, 1997; Friedrichs, 1998; Leventhal and Brooks-Gunn, 2000; Dietz, 2002; Sampson et al., 2002; Durlauf, 2004; Bolster et al., 2007). Galster (2011, in this volume) posited 15 different mechanisms through which the neighbourhood context can influence individual level outcomes. We summarise these mechanisms into two categories: internal neighbourhood mechanisms and external neighbourhood mechanisms.

The first group of mechanisms are internal to the neighbourhood and the best known example of such a mechanism is derived from the work of Wilson (1987) who documented the outcomes of individuals living in high poverty neighbourhoods in Chicago during the 1980s. He concluded that increasing concentrations of poverty in large public housing projects were creating a negative environment for residents, which was directly leading to further disadvantage and increased the propensity of unemployment. This is a so-called social-interactive mechanism (see Galster, 2011 this volume): if a neighbourhood environment lacks individuals with higher levels of education or employment other residents may lower their expectations about what they could achieve, or accept unemployment as a norm (see Manski, 2000; Blume and Durlauf, 2001; Brock and Durlauf, 2005; Bolster et al., 2007). Wilson's (1987) study is viewed by many as the starting point for much of the current neighbourhood effects research and the conclusions of his ethnographic research in Chicago are widely cited in the neighbourhood effects literature. However, Small and Feldman (2011, in this volume) questioned whether the theoretical pathways which have been developed in 
Chicago can be translated to other cities or national contexts as Chicago is an atypical rustbelt city in the USA.

The second group of mechanisms are external to the neighbourhood. Examples of these include the spatial mismatch hypothesis and stigmatisation based on neighbourhood reputations. The spatial mismatch hypothesis (Kain, 1968) suggests that individuals living in inner city neighbourhoods are unable to find employment because employment opportunities are inaccessible from the locations in which they live. Gobillon and colleagues (2005) identified seven mechanisms related to the spatial mismatch, four of which relate to the accessibility of employment for workers and include commuting costs, information access, incentive to search for work over large distances and high costs of searching beyond the immediate neighbourhood. As with the work of Wilson $(1987 ; 1991)$ the spatial mismatch hypothesis was developed in the context of Afro-American workers in the USA. However, research by van Ham (2002) and Houston (2001; 2005) has shown that the hypothesis can also be applied to other national contexts such as the Netherlands and the United Kingdom. The second external mechanism relates to neighbourhood reputations. Employers, banks, and other external agents tend to form opinions on the abilities and suitability of individuals based on the reputation of the neighbourhoods in which they live. Research has shown that individuals living in certain neighbourhoods are excluded from finance (see Aalbers, 2009) reducing their ability to obtain loans or mortgages for purchasing a car or a house. In terms of labour market outcomes, research has shown that neighbourhood reputations can detrimentally affect an individual's chances of getting a job (see Dean \& Hastings, 2000), because employers refuse to hire residents from certain neighbourhoods (see Wilson, 1991; Wacquant, 1993; Permentier et al., 2007). Stigma can become a structural barrier to gaining or keeping employment when it is institutionalised.

\section{Methodological considerations}

Studies consistently find that people living in deprived neighbourhoods are less likely than people in affluent neighbourhoods to do well in life. However, this does not necessarily mean that living in deprived neighbourhoods causes people to do less well. A major challenge in the empirical investigation of neighbourhood effects is the identification of causal relationships. Many studies which claim to have found causal neighbourhood effects are likely to have only found correlations between neighbourhood characteristics and individual outcomes, without clear evidence of the direction of causation. The literature distinguishes several econometric problems in the investigation of neighbourhood effects (see Moffitt, 2001).

The simultaneity problem, also referred to as Manski's reflection problem (Manski, 1993), arises when a researcher tries to infer whether the average behaviour in some group influences the behaviour of the individuals that make up the group. Problems with simultaneous causation may arise because the contextual conditions themselves may be the result of respondents' behaviour (endogenous effect). For example, if we are interested in whether a high level of unemployment in a neighbourhood causes residents to be more likely to be unemployed, an econometric problem arises because unemployed individuals in the neighbourhood contribute to the overall neighbourhood unemployment level. One solution is to relate past neighbourhood context (unemployment levels) to current (unemployment) outcomes. A second issue is the omitted-context-variables problem, also called the correlated unobservables problem. This problem refers to the omission of important context characteristics from a regression model which are correlated with included variables (at the neighbourhood level). If important variables are omitted, researchers might draw the wrong 
conclusions from the estimated effects of context variables which are included. A third problem is the endogenous membership problem. This problem also involves omitted variables, but this time relating to the individual. The core of this problem is self-selection into and out of neighbourhoods. Sorting into neighbourhoods is not based on a random process and if unobserved individual characteristics are correlated with both the location decision and the dependent variable, endogeneity occurs. In most studies it is likely that selective mobility into neighbourhoods leads to biased estimates of neighbourhood effects.

Bergström and van Ham (2011, this volume) suggest that neighbourhood mobility is highly structured and neighbourhood selection is strongly related to individual characteristics: individuals tend to move into neighbourhoods with populations which are similar to themselves. Individuals with greater financial resources will, all other things being equal, enter a neighbourhood in which the income of other residents is also relatively high. Those with a high income avoid neighbourhoods with a low average income or high levels of crime, anti-social behaviour or poor access to services. Bergström and colleagues, (2010) used Swedish data on moves over a 10 year period to show that neighbourhood self-selection is a key determinant of neighbourhood composition. As a result, it is likely that much previous evidence of neighbourhood effects is at least in part, attributable to selective mobility into and out of neighbourhoods. Cheshire (2007, p.2) succinctly summed up the problem by asking the question: "do poor people live in poor neighbourhoods because living in affluent ones costs too much? Or does living in a poor neighbourhood make poor people significantly poorer?”

The gold standard in avoiding selection bias is the use of (quasi) experimental data in which households are randomly assigned to neighbourhoods. There have been several poverty deconcentration programs in the US since the 1970s which operated a (quasi) experimental design. The best known are the Chicago Housing Association Gautreaux, the Moving to Opportunity (MTO) and Hope VI programs. Whilst the operational details of the programs differ, the overall idea behind the programs was similar: households living in concentrations of poverty in large scale housing projects were offered a number of different 'treatments' which included relocation from their current poor neighbourhood to a more affluent one using housing vouchers to access the private rental market, counselling for moving from welfare to work, and relocation in a regenerated neighbourhood. The idea behind the programs was that households who received 'treatment' would do better as a result of their move than they would have done had they remained living in their original neighbourhoods. Theoretically, participation in the relocation schemes was random with open selection criteria for households wishing to participate. As such, the relocation programs should provide an ideal test of whether or not neighbourhood characteristics affect the outcomes of individual life courses.

Some have criticised the findings of the large randomised trials discussed above, and have urged caution regarding the interpretation of research findings of these trials (see Moffit, 2001; Clark, 2008). In all programs only a small proportion of the households living in concentrations of poverty were given the means to move to more affluent suburban locations. In conjunction with the moves, households were offered counselling and support to assist with the move and finding employment and other opportunities in their new neighbourhoods. However, the main criticism relates to the selection into the programs and the support received. In all programs there were a number of criteria that residents had to fulfil in order to qualify for participation. For instance, in the Gautreaux program residents had to nominate themselves, and were not accepted if they had "more than four children, large debts or unacceptable housekeeping” (Rosenbaum, 1994, p.4). In addition the managers and counsellors of the program identified the families they felt were more likely to succeed and placed them in the better neighbourhoods, leaving the less suitable locations for less 
deserving families (Goering et al., 2002). This process placed self and institutional selection criteria on program participation neither of which are independent of the outcomes that the program sought to improve. Of the three projects, the MTO comes closest to an experimental design, with the fewest constraints on recruitment, although the selection was still far from random. It should also be noted that there is evidence that, although households changed their residential location, many tended to maintain contacts and use their old networks for education and employment opportunities and even return to their original neighbourhoods rather than integrate into their new neighbourhood locations and networks (Boyd et al., 2006). So although theoretically experimental designs are ideal for the study of neighbourhood effects, in practice they are very expensive and difficult to execute.

An additional challenge in neighbourhood effects research is the identification of the most appropriate spatial scale at which to measure neighbourhood characteristics. The meaning of neighbourhoods is highly contested (see Galster, 2001), although the issue of scale is frequently omitted from discussions in the empirical literature. Theoretical contributions highlight that the scale at which the neighbourhood is conceptualised is an important component of the neighbourhood effects thesis. Important questions relating to scale and neighbourhood boundaries are often not asked because administrative units are used as proxies for neighbourhoods driven by the availability of data. This is a problem because spatial scale should be driven by the mechanism and hypothesis under investigation. For example, testing hypotheses on the effect of neighbourhood reputation or neighbourhood stigma might require larger neighbourhood units than studies testing hypotheses on peer group effects. If models searching for neighbourhood effects incorrectly specify the spatial scale of neighbourhoods then it is possible that the modelled outcomes are unable to identify any effects simply because they do not operate at the scale chosen for the analysis (Manley, et al., 2006).

\section{Neighbourhood effects and labour market outcomes}

Musterd and Andersson (2005) used data from the Netherlands to investigate the impact of neighbourhood context on unemployment. They found that employed individuals living in neighbourhoods with a high proportion of people in receipt of welfare benefits were more likely to experience unemployment than individuals in neighbourhoods with a lower proportion of people in receipt of benefits. Their study gives some support to the hypothesis of negative socialisation as a source of neighbourhood effects. Repeating the analysis with Swedish data, Musterd and Andersson (2006) found similar results. After controlling for a range of individual characteristics they found that the probability of an individual remaining in unemployment increased with increasing levels of neighbourhood unemployment, up to the level of $16 \%$. Beyond this threshold, there was no additional effect on the probability of remaining unemployed. Using data from the 1991 Population Census of Great Britain, including information the individual level Sample of Anonymised Records, Clark and Drinkwater (2002) studied neighbourhood effects on employment outcomes for ethnic minorities in England and Wales. They reported that employment outcomes for ethnic minorities are related to the ethnic composition of the neighbourhood in which they live. Ethnic minority individuals living in ethnic enclaves are at a greater risk of experiencing unemployment compared to ethnic individuals in less ethnically concentrated areas. However, although Clark and Drinkwater were able to use individual data in the analysis, they note that they were unable to control for self-selection into areas with differing levels of ethnic concentration and that this may be behind some of the correlations found. 
The quasi-experimental studies mentioned before have produced a wealth of neighbourhood effects research on a wide range of outcomes (see for instance: Venkatesh, et al., 2004 for Gautreaux; Elhassan, et al,. 1999 for MTO; Ciseros \& Engdahl, 2009 for HOPE VI). Popkin and colleagues (1993) investigated outcomes for the Gautreaux programs and assessed how well black women from inner city housing projects performed in the labour market after moving to suburban neighbourhoods in Chicago. They found that residents who moved to the suburbs had an increased probability of finding employment, even when that individual had experienced long term unemployment in the past. However, although the probability of employment was higher, no differences were found in the wages of working women in the inner city and the suburb as the types of employment were similar in both locations. In a follow-up paper Mendenhall and colleagues (2006) concluded that the outcomes observed by Popkin and colleagues (1993) were maintained in the longer term: women who had relocated to suburban locations as a result of the Gautreaux program spent less time out of work, and were less likely to claim welfare assistance.

Assessing outcomes for the more extensive HOPE VI project, Popkin and Cunningham (2009) reported a mixed picture. Using data from the HOPE VI panel study they showed that the program resulted in dramatic improvements in the levels of well-being, including reduction in fear of crime and violence, for those residents who had moved to different neighbourhoods using housing vouchers to rent in the private market. The wellbeing outcomes contrast with the employment outcomes, where "there were no changes in employment or self sufficiency for private market renters, the few HOPE VI movers, or those who remained in traditional public housing” (Popkin and Cunningham, 2009, p.197), with unemployment remaining at $48 \%$ throughout the panel period.

The third of the major deconcentration programs, Moving to Opportunity (MTO), was initially assessed at 4 and 7 years after the randomised neighbourhood reassignment of participants. The interim study found that although there were improvements in satisfaction, perceptions of neighbourhood safety, and participant's mental health, there were no positive benefits for participation in the labour market. Moreover, for the male youth cohort there were reports of negative effects on behavioural outcomes despite the moves to neighbourhoods with lower concentrations of poverty (Orr et al., 2003). In a separate study, King, Liebman and Katz (2007) found similar labour market results to those of Orr and colleagues (2003) for individuals who had moved through the MTO program. The fact that the employment status of many relocated individuals did not improve over time, even when relocated to significantly better neighbourhoods in terms of violence, crime, unemployment and housing quality, raises doubt over the neighbourhood effects hypothesis in relation to employment outcomes.

Unfortunately, experimental and quasi-experimental data is rarely available, so a number of authors have attempted to use alternative methods to address the problem of selection bias while using observational data (see Oreopoulos, 2003; Bolster et al, 2007; van Ham and Manley, 2010). Oreopoulos (2003) used administrative data from Toronto to investigate labour market outcomes of adults who were assigned into various social housing projects during their childhood. The households the children lived in were assigned to dwellings in neighbourhoods which varied in levels of crime, unemployment and poverty. It can be argued that the selection mechanism was largely independent from the characteristics of the child and that the data is therefore quasi-experimental. Oreopoulos did not find any evidence of neighbourhood effects for adults who had grown up in social housing. However, for the control group, consisting of individuals in private housing in the same neighbourhoods, significant 'neighbourhood effects' were found. Oreopoulos concluded that those in private housing self-selected into neighbourhoods and that the correlations found were most likely selection effects and not causal neighbourhood effects. Similar results were 
found by Bolster and colleagues (2007), using data from the British Household Panel Survey (BHPS). They found small neighbourhood effects for those living in the private housing but no effects for those in social housing, although they do not explicitly discuss this outcome in their paper. Van Ham and Manley (2010) investigated the effect of living in deprived neighbourhoods and mixed tenure neighbourhoods on labour market outcomes using data from the Scottish Longitudinal Study. They found that living in a deprived neighbourhood is correlated with employment outcomes for those living in private housing, but not for those in social housing. They also concluded that self-selection into deprived neighbourhoods by homeowners with poor labour market prospects most likely caused the correlations found.

This chapter builds on the work of van Ham and Manley (2010). Instead of using a composite measure of neighbourhood deprivation we test a more specific hypothesis on the effects of living in neighbourhoods with high levels of unemployment (see Wilson, 1987; Musterd \& Andersson, 2005). As discussed in the introduction, according to the neighbourhood effect hypothesis it can be expected that those living in neighbourhoods with high levels of unemployment are less likely to be in contact with positive role models, are more likely to have unemployed friends and neighbours (which can lead to negative socialisation), are less likely to know people who can help finding a job, and are more likely to be stigmatised by outsiders. Thus, living in a neighbourhood with a high level of unemployment might make it harder for individuals out of work to get a job, and for those in employment to keep their job.

\section{Data and Methods}

We used individual level longitudinal data from the Scottish Longitudinal Study (SLS). The SLS is an anonymised 5.3\% sample of the Scottish population with matched census records from 1991 and 2001 (Boyle et al., 2008). The sample gives approximately 274,000 SLS members available for analysis. The SLS members are geocoded which allows researchers to link individual records to neighbourhood characteristics at a low geographic scale. The longitudinal structure of the data is highly appropriate for neighbourhood effects research as it enables researchers to follow individuals and investigate the effects of 1991 characteristics on their 2001 outcomes.

For the analysis presented in this chapter, the SLS population is restricted to include only those individuals aged between 15 and 50 years old in 1991, and only those individuals who were available for paid employment in both 1991 and 2001. This means that those who were students, retired or permanently ill in 1991 were excluded from the analysis. For employed individuals, part time and full time work are coded as employed with no distinction made between the two categories. We have also included individuals who had secured a job but not yet started it as employed. A restriction of the data is that we have no information on what an individual's employment situation was between the data points in 1991 and 2001. So, for example, if an individual was unemployed for the 1991 and 2001 Census days but had employment for the whole of the period in-between they would appear identical in our employment variable as an individual who had been unemployed through the whole time. Although this is a serious limitation of the data, we feel that size of the data set, the low level geocoding, and the longitudinal nature of the data outweigh the problems posed by the lack of information between the time points.

The outcome variables used in this study measure employment status in 2001. In the first set of models we investigated the probability of having a job in 2001 for those individuals who were unemployed in 1991. Those individuals who remained unemployed in 2001 were coded 0 and those who had a job in 2001 were coded 1. In the second set of 
models we investigated the probability that those individuals who were employed in 1991 are unemployed in 2001. Thus, from those who were employed in 1991 the outcome of still being employed in 2001 is coded 0, while those individuals who were unemployed in 2001 are coded 1 . Since both dependent variables are binary we have used logistic regression models, with a correction for the clustering of individuals in neighbourhoods.

Quantitative studies using secondary data rely on administrative spatial units when making neighbourhoods operational (see Kearns and Parkinson, 2001; Galster 2001; Manley et al., 2006). In many neighbourhood effects studies there is a mismatch between the spatial level at which the theoretical causal mechanism is thought to operate and the spatial level at which neighbourhoods have been made operational. Many studies use relatively large neighbourhoods because lower level geocoding was not available in the data used. In this study we investigate the effect of neighbourhood unemployment levels on individual employment outcomes. The literature identifies several causal mechanisms through which the neighbourhood context can have an effect on employment outcomes and these mechanisms can operate on different spatial scales. For instance, (negative) role model effects can be expected to operate on a relatively low spatial scale. Direct neighbours are probably more important than those living a few blocks away. Local networks through which people might find employment can also be expected to operate on a relatively low spatial level as these networks often need face-to-face interaction. Stigmatisation of neighbourhood residents by outsiders based on the reputation of the neighbourhood is likely to operate at the level of larger neighbourhood units. Because of the variety of spatial scales at which causal mechanisms might be at play we use two definitions of neighbourhoods (see also Graham et al., 2009; van Ham \& Manley, 2010). The first neighbourhood scale uses Output Areas (OAs), which contain around 119 people on average. The second neighbourhood scale uses Continuous Areas Through Time (CATTs) which are much larger and contain around 503 people on average.

Two neighbourhood characteristics are included in the models, both of which are measured in 1991 at the OA and CATT level. We measured neighbourhood characteristics in 1991 to minimise problems with reversed causality: in our design, individuals lived in their neighbourhoods prior to any change in their labour market status. Although we cannot be certain of identifying causal pathways this way, we can be relatively confident that any neighbourhood effects we observe are more than merely correlations. The main neighbourhood level characteristic in the models is the percentage of unemployed individuals in the neighbourhood in 1991. This is calculated by dividing the number of 16-64 year old people who are looking for employment by the total number of people available for work in that age group. The neighbourhood effects literature suggests that, when unemployment levels reach a certain critical level (threshold), it is more likely that individuals will be affected by negative socialization and negative role models. It has also been suggested that neighbourhoods with high levels of unemployment are more likely to suffer from negative external reputations and that individuals searching for work whilst living in such neighbourhoods are less likely to find work because employers are reluctant to employ them. Neighbourhood unemployment is categorized into 5 groups: $0-1.9 \%$; $1.9-3.6 \%$; 3.64-6.0\%; 6.0-10.1\%, and; $10.1-54.9 \%$ (for reference the national average level of unemployment recorded in the 1991 Census for Scotland was 6.2\%). We have used categories for the variable to account for the possibility that any relationship is non-linear.

The second neighbourhood characteristic included in the models is an urban-rural classification which serves as a proxy for access to job opportunities (see also van Ham, 2002). The urban-rural classification is based on population size and access to concentrations of population (Scottish Executive, 2004) and measured in six categories: (i) cities (over 125,000 people); (ii) urban areas (10,000 to 125,000 people); (iii) small towns (3000 to 
10,000 people or within 30 min from towns with 10,000 people or more); (iv) remote towns (3000 to 10,000 people over 30 min from settlement of over 10,000); (v) accessible rural (less than 3000 people and within 30 min from places with over 10,000 people); and (vi) remote (settlements with under 3000 people, over $30 \mathrm{~min}$ from places with over 10,000 people).

We also included a range of individual level control variables in our models. These include dichotomized variables for gender, ethnicity, limiting long term illness, household status, housing tenures and educational outcomes. An individual's age is included as a continuous variable. To minimise causality issues, all control variables are measured for 1991. Summary statistics of all variables can be found in Table 1.

$<$ Table 1 about here>

\section{Modelling results}

Table 2 reports models of the probability that those who were unemployed in 1991 also had a job in 2001. Models 1 and 2 include neighbourhood characteristics on the CATT level and Models 3 and 4 include neighbourhood characteristics measured at the Output Area level. Model 1 shows that the probability of getting a job in 2001 decreases as the level of unemployment in the 1991 neighbourhood of residence increases. Those living in neighbourhoods with more than 10\% unemployment are the least likely to have a job in 2001 . Although we use longitudinal data, we cannot be certain that the effects found are causal effects. A major cause of potential bias is the self-selection of residents into neighbourhoods prior to 1991.

Model 2 also controls for a large range of individual and household characteristics and includes a job access proxy in the form of an urban to rural classification scheme. Including all these control variables in the model reduces the size of the neighbourhood unemployment parameters, but the general pattern stays the same. The model results show that unemployed women in 1991 are much more likely than unemployed men to have a job in 2001. We did not find an effect for ethnicity. One possible explanation is that the number of individuals in the data who belong to ethnic minority groups is very low and that we combined all individuals who were indentified in the Census as non-white in one category. Differences in labour market performance between ethnic minorities might therefore average out. With increasing age, unemployed people are less likely to have a job 10 years later.

Individuals who were unemployed in 1991 and who are single in both 1991 and 2001 are the least likely to get a job in 2001. This is probably an example of reversed causation where unemployed people are also less likely than employed people to find a partner. Also those who split up from their partner between 1991 and 2001 have a reduced probability of being employed in 2001. People without children in both years are less likely than others to have a job in 2001. Again, this is probably a case of reversed causality. As expected, level of education is an important predictor of 2001 employment. Having at least basic school level qualifications or better, compared with individuals without qualifications, significantly improves an individual's chances of having a job in 2001. The effects of individual level education are relatively large compared with the effects of the neighbourhood level characteristics. Finally, social renters and private renters are less likely to have a job in 2001 compared with homeowners. Model 3 and 4 in Table 2 include neighbourhood level variables at the Output Area level. As explained before, Output Areas are much smaller spatial units than CATTs. Interestingly, the overall results for the Output Area level analyses are very similar to the CATT area analyses. Most other research using more than one spatial level in their modelling reported stronger effects at the lower geographies. 
$<$ Table 2 about here>

Table 3 reports models of the probability that those who were employed in 1991 are unemployed in 2001. Again, Models 5 and 6 include neighbourhood characteristics for the CATT neighbourhoods and Models 7 and 8 include characteristics for neighbourhoods represented by Output Areas. Model 5 shows a strong correlation between neighbourhood unemployment levels and the probability of being unemployed in 2001. The higher the neighbourhood unemployment levels, the less likely employed people are to still have a job in 2001. Adding control variables in Model 6 does not alter the overall pattern of the main variable of interest, but the parameters are much smaller and not all significant.

Model 6 also includes a range of control variables. Females are less likely to be out of work than males. Those belonging to ethnic minority groups are more likely than non-ethnic minority individuals to be out of employment in 2001. With increasing age the probability of being out of employment in 2001 increases. Those who were single in both 1991 and 2001 and those who became single between the two Census years are the most likely to be unemployment in 2001. Those without children in both Census years are more likely than those with kids to be out of employment in 2001. Having qualifications greatly reduces the probability of becoming unemployed. Those with degrees are the least likely to be out of employment. Private renters and especially social renters are much more likely than home owners to be out of employment in 2001. A possible explanation is selection into tenures where those with better employment prospects are the most likely to be homeowners in the first place. As expected, individuals with poor health in both Census years, along with those whose health deteriorates between 1991 and 2001, are more likely to be out of work than those with good health. Again we repeat the models including Output Area level variables. Model 7 shows that the results of the models including Output Area level neighbourhood characteristics are very similar to the results of the models including CATT level neighbourhood characteristics.

$<$ Table 3 about here $>$

Stopping the analysis here could lead to the confirmation of the neighbourhood effects hypothesis as we have found significant 'effects' of neighbourhood unemployment levels on individual employment outcomes. However, earlier in this chapter we have argued that modelling employment outcomes separately for social renters and homeowners can provide more insight in whether the correlations found are indeed causal effects (see Oreopolous, 2003; van Ham \& Manley, 2010). Table 4 presents tenure split models including neighbourhood characteristics at the CATT level (the results at the OA level were very similar). Models 9 to 12 estimate the probability of getting a job in 2001 for those who were out of work in 1991. Models 9 and 10 only include social renters and models 11 and 12 only include owner occupiers. The main difference between the models for social renters and the models for owner occupiers is that we found hardly any significant effects of neighbourhood unemployment levels for social renters, while for owner occupiers the significant effects seen previously in table 2 are still present. For social renters we only found a significant effect on employment outcomes of living in neighbourhoods with the highest levels of unemployment. Models 13 to 16 estimate the probability that those with a job in 1991 are out of employment in 2001. Models 13 and 14 only include social renters and models 15 and 16 only include owner occupiers. Again we find that there are more significant effects of living in a high unemployment neighbourhood on labour market outcomes for owner occupiers than for social renters. The overall pattern in Table 4 is that we find relatively strong correlations 
between neighbourhood unemployment levels and employment outcomes for owner occupiers, but not for social renters. It is unlikely that neighbourhood effects only influence owner occupiers and that social renters in the same neighbourhoods are immune to neighbourhood effects. As a result, alternative explanations must be explored, including the possibility that the effects of selection bias are stronger for owner occupiers than for social renters.

$<$ Table 4 about here>

\section{Discussion}

In this chapter we investigated the hypothesis that living in neighbourhoods with a high level of unemployment can negatively affect the labour market prospects of neighbourhood residents. Several theoretical causal pathways were suggested through which the neighbourhood context could influence individual outcomes: those living in neighbourhoods with high levels of unemployment are less likely to be in contact with positive role models, are more likely to have unemployed friends and neighbours which might cause negative socialisation, are less likely to know people who can help finding a job, and are more likely to be stigmatised by outsiders. We used longitudinal data to study the effect of 1991 neighbourhood characteristics on 2001 labour market outcomes. As expected, we found a strong correlation between neighbourhood unemployment levels and individual labour market outcomes 10 years later, even after controlling for a range of individual and household characteristics. These results could lead to the conclusion that there are strong causal neighbourhood effects at play.

However, the data used from the Scottish Longitudinal Study did not allow us to control our results for self-selection of individuals into neighbourhoods prior to 1991, a process that is likely to be correlated with individual level labour market outcomes. To overcome this restriction and to gain greater insight into potential selection mechanisms we estimated tenure split models which showed significant effects of neighbourhood unemployment levels on labour market outcomes for owner occupiers, but not for social renters. Previously, similar effects were found by Oreopoulos (2003) and Van Ham and Manley (2010). Intuitively, one would expect negative neighbourhood effects for social renters and not for owner occupiers. It was suggested that the effects found are related to the differences in mechanisms through which social renters and owner occupiers 'select' their neighbourhoods. In Scotland, social renters before the early 1990s were largely randomly allocated a dwelling by a housing officer, without the option to express any choice with regard to dwelling or neighbourhood. We do acknowledge however that allocation was not completely random as ethnicity, household size, and household structure all played a role in the allocation process (Duke, 1970; Simpson, 1981; Henderson \& Karn, 1984; Clapham \& Kintrea, 1984; Malpass \& Murie, 1994; Peach, 1996; Somerville, 2001; Sarre et al., 1989). As a result of the allocation process in social housing, it is reasonable to argue that selection bias is less likely to influence model outcomes for social renters than for owner occupiers. Owner occupiers had greater freedom in choosing where they wanted to live within the restrictions of their own budget and the constraints of the local housing market. Mortgage providers play an important indirect role in neighbourhood selection by homeowners as they determine how much an applicant can borrow and therefore which houses in which neighbourhoods are affordable (see Aalbers, 2009). Mortgage providers look at individual and household income, but also at job security and potential career development. Those with the least secure jobs get the lowest mortgages and therefore select themselves into the 
cheapest neighbourhoods, often neighbourhoods with high unemployment levels. Thus, labour market outcomes are also driving the selection of neighbourhoods by households in the owner-occupied sector.

The tenure split models suggest that the correlations found between neighbourhood unemployment levels and individual unemployment are, at least in part, the result of selection bias. To enable neighbourhood effects research to move forward, it is necessary to incorporate the neighbourhood selection process into models of neighbourhood effects. Such an approach requires richer longitudinal data than currently available in most datasets. Where it is not possible to model neighbourhood selection before modelling the impact of neighbourhood characteristics on individual outcomes, an approach such as the one explored in this chapter is recommended.

Moving beyond the question of whether or not correlations between neighbourhood characteristics and individual outcomes are the result of causal pathways or selection effects, it is important to remember that concentrations of unemployment and poverty in neighbourhoods are real. The question of whether and how to tackle these concentrations of poverty is more than an academic and methodological question. It is also a question of social and spatial justice (Smith, 1994; Soja, 2010). The lack of a causal pathway between neighbourhood context and individual outcomes does little to solve the problems of uneven neighbourhood resources. Nevertheless, the realisation that individual outcomes, in the case of this chapter individual unemployment, are not exacerbated by living in concentrations of unemployment is important. Policy prescriptions, such as reducing the concentration of social housing to deconcentrate poverty, and by default unemployment, will most likely not by itself lead to significant improvements in individual outcomes. This argument does not mean that neighbourhoods with high concentrations of poverty or other perceived social problems should not be invested in or offered regeneration. Rather, it is necessary to recognise the limitations of such policies with respect to the impact they will have on individuals and the limited potential they have to improve individual outcomes. The empirical results shown in this chapter highlight the importance of, amongst other things, an individual's educational achievement as a means through which their chances of employment increase significantly. As a result, policies that specifically target individuals are more likely to offer real outcomes and tangible changes in individual life courses.

\section{Acknowledgements}

The help provided by staff of the Longitudinal Studies Centre-Scotland (LSCS) is acknowledged. The LSCS is supported by the ESRC/JISC, the Scottish Funding Council, the Chief Scientist's Office and the Scottish Executive. The authors alone are responsible for the interpretation of the data. Census output is Crown copyright and is reproduced with the permission of the Controller of HMSO and the Queen's Printer for Scotland.

\section{References}

Aalbers, M.B. (2009) Redlining. In: N. Thrift and R. Kitchin (Eds) International encyclopaedia of human geography, Volume X, (pp. 117-124). Oxford: Elsevier.

Bergström, L. \& van Ham (2011) The impacts of residential mobility on measurements of neighbourhood effects. In: van Ham, M., Manley, D., Bailey, N., Simpson, L., \& Maclennan, D. Neighbourhood Effects Research: New Perspectives. Dordrecht: Springer. 
Bergström, L., van Ham, M. \& Manley, D. (2010) Neighbourhood reproduction through neighbourhood choice, Paper presented at meeting of the European Network for Housing Research, Istanbul, Turkey, July 2010.

Blume, L. \& Durlauf, S. (2001) The interactions-based approach to socioeconomic behaviour. In: S. Durlauf and H. P. Young (Eds.) Social Dynamics, (pp. 15-44). Cambridge: MIT Press.

Bolster, A., Burgess, S., Johnston, R., Jones, K., Propper, C., \& Sarker, R. (2007) Neighbourhoods, households and income dynamics: a semi-parametric investigation of neighbourhood effects. Journal of Economic Geography, 7(1), 1-38.

Boyd, M., Edin, K., Duncan, G \& Clampet-Lundquist, S. (2004) The Durability of the Gautreaux Two Residential Mobility Program: A qualitative analysis of who stays and who moves from low-poverty neighbourhoods. Population Association of American, Annual Meeting. Los Angeles 30 ${ }^{\text {th }}$ March, 2006. paa2006.princeton.edu/download.aspx?submission $\mathrm{Id}=61724$. Accessed 3 June 2010.

Boyle, P. J., Feijten, P., Feng, Z., Hattersley, L., Huang, Z., Nolan, J., Raab, G. (2008) Cohort profile: the Scottish Longitudinal Study (SLS). International Journal of Epidemiology 38(2): 385-392.

Brock, W. \& Durlauf, S. (2001) Interactions-based models. In: J. Heckman \& E. Leamer (eds) Handbook of Econometrics Volume 5, (pp. 3297-3380), Amsterdam: Elsevier Science B.V.

Cheshire, P. (2007) Are mixed communities the answer to segregation and poverty? York: Joseph Rowntree Foundation.

Cheshire, P. (2011) Policies for Mixed Communities: Still Looking for Evidence? In: van Ham, M., Manley, D., Bailey, N., Simpson, L., \& Maclennan, D. Neighbourhood Effects Research: New Perspectives. Dordrecht: Springer.

Ciseros, H. G., \& Engdahl, L (Eds) (2009) From Despair to Hope: HOPE VI and the New Promise of Public Housing in America's Cities. Washington D. C: The Brookings Institution.

Clapham, D. \& K. Kintrea (1984) Allocation Systems and Housing Choice, Urban Studies, 21(3): 261-269.

Clark, W. A. V. (2008) Re-Examining the Moving to Opportunity Study and Its Contribution to Changing the Distribution of Poverty and Ethnic Concentration. Demography, 45(3): 515535.

Clark, K., \& Drinkwater, S. (2002) Enclaves, Neighbourhood Effects and Employment Outcomes: Ethnic Minorities in England and Wales. Journal of Population Economics, 15(1): 5-29.

Dean, J., \& Hasting, A (2000) Challenging Images: Housing estates, stigma and regeneration. Bristol: Policy Press. 
Dietz, R. D. (2002) The estimation of neighborhood effects in the social sciences: an interdisciplinary approach. Social Science Research, 31(4): 539-575.

Duke, C. (1970) Colour and Rehousing: a study of redevelopment in Leeds. London: Institute of Race Relations.

Durlauf, S. (2004) Neighborhood effects. In: J. V. Henderson \& J.-F. Thisse (Eds.), Handbook of Regional and Urban Economics, Vol. 4 Cities and Geography, (pp.2173-2242). Amsterdam: Elsevier Science B.V.

Elhassan, H., Feins, J., Goering, J., Holin, M, J., Kraft, J. \& McInnis, D. (1999) Moving to Opportunity for Fair Housing Demonstration Program: Current Status and Initial Findings. Washington D. C: U.S. Department of Housing and Urban Development.

Ellen, I. G., \& Turner, M. A. (1997) Does neighbourhood matter? Assessing recent evidence. Housing Policy Debate, 8(4): 833-866.

Friedrichs, J. (1998) Do poor neighborhoods make their residents poorer? Context effects of poverty neighborhoods on their residents. In: H. Andress (Ed.) Empirical Poverty Research in a Comparative Perspective. (pp.77-99). Aldershot: Ashgate.

Galster, G. (2001) On the Nature of Neighbourhood, Urban Studies, 38(12): 2111-2124.

Galster, G. (2011) The Mechanism(s) of Neighbourhood Effects: Theory, Evidence, and Policy Implications. In: M van Ham, D Manley, N Bailey, L Simpson, D Maclennan. Neighbourhood Effects Research: New Perspectives. (pp.XX-XX) Dordrecht: Springer.

Gobillon, L., Selod, H., \& Zenou, Y. (2005) The mechanisms of spatial mismatch. Research Unit Working Papers 0510, Laboratoire d'Economie Appliquee, INRA.

Goering, J., Feins, J. D., \& Richardson, T. M. (2002) A cross-site analysis of initial moving to opportunity demonstration results. Journal of Housing Research, 13(1): 1-30.

Graham, E., Manley, D., Hiscock, R., Boyle, P., \& Doherty, J. (2009) Mixing housing tenures: is it good for social well-being? Urban Studies, 46(1): 139-165.

Henderson, J., \& Karn, V. (1984) Race, class and the allocation of public housing in Britain, Urban Studies, 21(1): 115-128.

Houston, D. S. (2001) Testing the Spatial Mismatch Hypothesis in the United Kingdom Using Evidence from Firm Relocations, European Research in Regional Science, 11(1): 134151.

Houston, D. S. (2005) Employability, Skills Mismatch and Spatial Mismatch in Metropolitan Labour Markets. Urban Studies, 42(2): 221-243.

Kain. J. F. (1968) Housing Segregation, Negro Employment, and Metropolitan Decentralization, Quarterly Journal of Economics, 82(1): 175-197. 
Katz, L., Kling, J., \& Liebman, J. (2001) Moving to opportunity in Boston: early results of a randomized mobility experiment. Quarterly Journal of Economics, 116(2): 607-654.

King, J. R., Liebman, J. B., \& Katz, L. F. (2007) Experimental Analysis of Neighborhood Effects, Econometrica, 75(1): 83-119.

Leventhal, T., \& Brooks-Gunn J. (2000) A Randomized Study of Neighborhood Effects on Low-Income Children's Educational Outcomes. Developmental Psychology, 40(4): 488-507.

Ludwig, J., Duncan, G. J., \& Hirschfield, P. (2001) Urban poverty and juvenile crime: evidence from a randomized housing-mobility experiment. Quarterly Journal of Economics, 116(2): 655-680.

Malpass, P. \& Murie, A. (1994) Housing Policy and Practice, 4th edition. London: MacMillan Press.

Manley, D., Flowerdew, R. \& Steel D. (2006) Scales, levels and processes: Studying spatial patterns of British census variables. Computers, Environment and Urban Systems, 30(2): 143160.

Manski, C. (1993) Identification of endogenous social effects: the reflection problem, Review of Economic Studies, 60(3): 531-542.

Manski, C. (2000) Economics analysis of social interactions. Journal of Economic Perspectives, 14(1): 115-136.

Mendenhall, R., Duncan, G.J., \& DeLuca, S. A. (2006) Neighborhood Resources, Racial Segregation, and Economic Mobility: Results from the Gautreaux Program. Social Science Research, 35(6): 892-923.

Moffit, R. (2001) Policy Interventions, Low-level Equilibria, and Social Interactions. In: Durlauf, S. \& Young, H. (Eds.) Social Dynamics. (pp.45-82) London: MIT Press.

Musterd, S., \& Andersson, R. (2005) Housing mix, social mix and social opportunities. Urban Affairs Review, 40(6): 761-790.

Musterd, S., \& Andersson, R. (2006) Employment, Social Mobility and Neighbourhood Effects: The Case of Sweden. International Journal of Urban and Regional Research. 30(1): 120-140.

Musterd, S,. Ostendorf, W., \& De Vos, S (2003) Neighbourhood effects and social mobility: a longitudinal analysis. Housing Studies, 18(6): 877-892.

Oreopoulos, P. (2003) The long-run consequences of living in a poor neighborhood. Quarterly Journal of Economics, 118(4): 1533-1575.

Orr, Larry, Judith D. Feins, Robin Jacob, Erik Beecroft, Lisa Sanbonmatsu, Lawrence F. Katz, Jeffrey B. Liebman, \& Jeffrey R. Kling (2003) Moving to Opportunity Interim Impacts Evaluation. Washington, DC: U.S. Department of Housing and Urban Development, Office of Policy Development and Research. 
Overman, H. G. (2002) Neighbourhood effects in large and small neighbourhoods. Urban Studies, 39(1): 117-130.

Peach, C. (1996) Does Britain have ghettos? Transactions of the Institute of British Geographers, 21(1): 216-235.

Permentier, M., Van Ham, M., Bolt G. (2007) Behavioural responses to neighbourhood reputations, Journal of Housing and the Built Environment, 22(2): 199-213.

Popkin, S. J. \& Cunningham, M. K. (2009) Has HOPE VI Transformed Residents' Lives. In: Cisneros, H. L. \& Lora, Engdahl (Eds) From Despair to Hope: HOPE VI and the New Promise of Public Housing in America's Cities. (pp.191-205), Washington D. C.: Brookings Institute Press.

Popkin, S. J., Rosenbaum, J. E., \& Meaden, P. M., (1993) Labor Market Experiences of LowIncome Black Women in Middle-Class Suburbs: Evidence from a Survey of Gautreaux Program Participants. Journal of Policy Analysis and Management, 12(3): 556-573.

Rosenbaum, J. (1994) Housing mobility strategies for changing the geography of opportunity. Evanston: Institute for Policy Research, Northwestern University.

Rosebaum, J. (1995) Changing the geography of opportunity by expanding residential choice: lessons from the gatreaux program. Housing Policy Debate, 6(1): 231-269.

Sampson, R., Morenoff, J., and Gannon-Rowley, T., (2002) Assessing 'neighbourhood effects': Social processes and new directions in research, Annual Review of Sociology, 28: 443-478.

Simpson, A. (1981) Stacking the decks. Nottingham: Nottingham Community Relations Council.

Sarre, P., Phillips, D., \& Skellington, R. (1989) Ethnic Minority Housing: Explanations and policies. Aldershot: Avebury.

Simpson, L., Purdam, K., Tajar, A., Fieldhouse, E., Gavalas, V., Tranmer, M., Pritchard, J., \& Dorling, D. (2006) Ethnic Minority Populations and the Labour Market: An Analysis of the 1991and 2001 Census. London: DWP Report No. 33.

Small, M \& Feldman, J. (2011) Ethnographic Evidence and Neighbourhood Effects: Strong and Weak Approaches to Testing Propositions from the Field. In: M van Ham, D Manley, N Bailey, L Simpson, D Maclennan. Neighbourhood Effects Research: New Perspectives. Dordrecht: Springer.

Smith, D, M. (1994) Geography and Social Justice. Blackwell: Oxford.

Soja, E. W. (2010) Seeking Spatial Justice. University of Minnesota Press, Minneapolis. 
Somerville, P. (2001) Allocating housing or letting people choose? In: D Cowan \& A Marsh (Eds) Two Steps Forward: Housing Policy Into the New Millennium, (pp.113-132), Bristol: Policy Press.

van der Klaauw, B. \& Ours, J. (2003) From welfare to work: does the neighborhood matter? Journal of Public Economics, 87(5-6): 957-985.

van Ham M. (2002) Job access, workplace mobility, and occupational achievement. Delft: Eburon.

van Ham, M. \& Manley, D. (2010) The effect of neighbourhood housing tenure mix on labour market outcomes: a longitudinal investigation of neighbourhood effects. Journal of Economic Geography. 10(2): 257-282.

Venkatesh, S.A., Celimli, I., Miller, D., Murphy, A., \& Turner, B., (2004) Chicago Public Housing Transformation: A Research Report. New York: Center for Urban Research, Columbia University.

Wacquant, L. J. D. (1993) Urban outcasts: stigma and division in the black American ghetto and the French periphery. International Journal of Urban and Regional Research, 17(3): 366-383.

Wilson, W. J. (1987) The Truly Disadvantaged. Chicago: University of Chicago Press.

Wilson, W. J. (1991) Another look at the truly disadvantaged. Political Science Quarterly, 106(4): 639-656. 
Table 1. Variable summary statistics

\begin{tabular}{|c|c|c|c|c|}
\hline & \multicolumn{2}{|c|}{$\begin{array}{c}\text { Unemployed in } 1991 \\
\mathrm{~N}=3,639\end{array}$} & \multicolumn{2}{|c|}{$\begin{array}{c}\text { Employed in } 1991 \\
\quad \mathrm{~N}=60,048\end{array}$} \\
\hline Percentage employed in 2001 & \multicolumn{2}{|c|}{$71.7 \%$} & \multicolumn{2}{|c|}{$97.5 \%$} \\
\hline & $\mathrm{OA}(\%)$ & CATT (\%) & OA (\%) & CATT (\%) \\
\hline \multicolumn{5}{|l|}{ Neighbourhood level variables } \\
\hline Neighbourhood Unemployment 1991 (ref = 0-1.9\%) & 8.4 & 6.8 & 17.8 & 15.6 \\
\hline $1.9-3.5 \%$ & 13.5 & 12.3 & 22.2 & 23.4 \\
\hline $3.6-5.9 \%$ & 19.5 & 18.1 & 23.2 & 22.8 \\
\hline $5.9-10.0 \%$ & 28.8 & 24.2 & 19.9 & 21.1 \\
\hline $10.1-54.9 \%$ & 29.8 & 38.7 & 16.9 & 17.1 \\
\hline 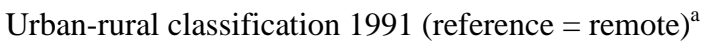 & 4.4 & 4.4 & 5.2 & 5.2 \\
\hline Accessible Rural Areas & 10.2 & 10.2 & 13.5 & 13.5 \\
\hline Remote Towns & 1.9 & 1.9 & 2.7 & 2.7 \\
\hline Small Towns & 10.0 & 10.0 & 10.7 & 10.7 \\
\hline Urban Areas & 31.2 & 31.2 & 31.2 & 31.2 \\
\hline Cities & 42.3 & 42.3 & 36.7 & 36.7 \\
\hline \multicolumn{5}{|l|}{ Individual and Household level variables } \\
\hline Qualifications 1991 (reference = none) & & 85.3 & & 76.2 \\
\hline Less than degree & & 2.6 & & 10.6 \\
\hline Degree or better & & 2.6 & & 8.4 \\
\hline Not stated & & 5.2 & & 2.2 \\
\hline Tenure 1991 (reference = owners) & & 34.7 & & 69.5 \\
\hline Social Renter & & 58.1 & & 24.3 \\
\hline Private Renter & & 7.2 & & 6.2 \\
\hline Age (average age in 1991) & & 28.9 years & & 32.9 years \\
\hline Female (reference = male) & & 33.2 & & 44.3 \\
\hline Ethnic (reference = non ethnic) & & 0.9 & & 0.7 \\
\hline Partner Works 1991 (reference = not work) & & 55.9 & & 77.1 \\
\hline Change in health (reference $=$ no LLTI) & & 88.5 & & 92.6 \\
\hline LLTI 91 \& 01 & & 1.1 & & 0.8 \\
\hline LLTI 91 & & 2.1 & & 0.9 \\
\hline LLTI 01 & & 8.3 & & 5.7 \\
\hline Change in Household Type (reference = couple) & & 55.4 & & 73.9 \\
\hline $91 \& 01$ Single & & 9.4 & & 4.8 \\
\hline 91 Single / 01 Couple & & 4.4 & & 3.7 \\
\hline 91 Couple / 01 Single & & 30.8 & & 17.6 \\
\hline Change in presence of children (reference = Children) & & 24.4 & & 25.6 \\
\hline 91 / 01 No Children & & 41.1 & & 33.1 \\
\hline 91 No Child / 01 Child & & 14.9 & & 16.7 \\
\hline 91 Child / 01 No Child & & 19.6 & & 24.6 \\
\hline Moved (reference = not moved) & & 69.5 & & 62.1 \\
\hline
\end{tabular}


Table 2. Logistic regression of the probability of employment in 2001 for those unemployed in 1991

\begin{tabular}{|c|c|c|c|c|c|c|c|c|c|c|c|c|}
\hline & \multicolumn{6}{|c|}{ CATT level } & \multicolumn{6}{|c|}{ OA level } \\
\hline & \multicolumn{3}{|l|}{ Model 1} & \multicolumn{3}{|l|}{ Model 2} & \multicolumn{3}{|l|}{ Model 3} & \multicolumn{3}{|l|}{ Model 4} \\
\hline & Coef. & S.e. $^{\mathrm{b}}$ & & Coef. & S.e. $^{b}$ & & Coef. & S.e. $^{b}$ & & Coef. & S.e. $^{\mathrm{b}}$ & \\
\hline \multicolumn{13}{|c|}{ Neighbourhood level variables } \\
\hline \multicolumn{13}{|c|}{ Neighbourhood Unemployment 1991 (reference $=0-1.9 \%$ ) } \\
\hline $1.9-3.5 \%$ & -0.353 & 0.249 & & -0.237 & 0.278 & & -0.534 & 0.294 & $*$ & -0.381 & 0.320 & \\
\hline $3.6-5.9 \%$ & -0.741 & 0.230 & $* * *$ & -0.486 & 0.264 & $*$ & -0.550 & 0.278 & $* *$ & -0.348 & 0.302 & \\
\hline $6.0-10.0 \%$ & -1.094 & 0.223 & $* * *$ & -0.762 & 0.257 & $* * *$ & -1.083 & 0.265 & $* * *$ & -0.717 & 0.292 & $* * *$ \\
\hline $10.1-54.9 \%$ & -1.278 & 0.218 & $* * *$ & -0.882 & 0.253 & $* * *$ & -1.347 & 0.260 & $* * *$ & -0.865 & 0.291 & $* * *$ \\
\hline \multicolumn{13}{|c|}{ Urban-rural classification 1991 (reference = Cities) } \\
\hline Urban Areas & & & & -0.008 & 0.107 & & & & & -0.009 & 0.107 & \\
\hline Small Towns & & & & -0.003 & 0.159 & & & & & 0.056 & 0.154 & \\
\hline Remote Towns & & & & 0.275 & 0.318 & & & & & 0.318 & 0.321 & \\
\hline Rural Areas & & & & 0.076 & 0.171 & & & & & 0.122 & 0.169 & \\
\hline Remote Areas & & & & -0.209 & 0.220 & & & & & -0.175 & 0.222 & \\
\hline \multicolumn{13}{|c|}{ Individual and Household level variables } \\
\hline Female (reference $=$ male) & & & & 0.848 & 0.112 & $* * *$ & & & & 0.842 & 0.110 & $* * *$ \\
\hline Ethnic (reference $=$ non et & nic) & & & -0.170 & 0.475 & & & & & -0.195 & 0.477 & \\
\hline Age in years (1991) & & & & -0.015 & 0.005 & $* * *$ & & & & -0.015 & 0.005 & $* * *$ \\
\hline \multicolumn{13}{|c|}{ Change in Household Type (reference = couple) } \\
\hline 91 \& 01 Single & & & & -1.105 & 0.145 & $* * *$ & & & & -1.092 & 0.147 & $* * *$ \\
\hline 91 Single / 01 Couple & & & & 0.327 & 0.257 & & & & & 0.348 & 0.258 & \\
\hline 91 Couple / 01 Single & & & & -0.744 & 0.105 & $* * *$ & & & & -0.737 & 0.103 & $* * *$ \\
\hline \multicolumn{13}{|c|}{ Change in presence of children (reference $=$ children) } \\
\hline 91 / 01 No Children & & & & -0.346 & 0.124 & $* * *$ & & & & -0.348 & 0.125 & $* * *$ \\
\hline 91 No Child / 01 Child & & & & 0.184 & 0.166 & & & & & 0.188 & 0.168 & \\
\hline 91 Child / 01 No Child & & & & 0.010 & 0.147 & & & & & 0.004 & 0.145 & \\
\hline \multicolumn{13}{|c|}{ Qualifications 1991 (reference $=$ none) } \\
\hline Less than degree & & & & 0.633 & 0.315 & $* *$ & & & & 0.638 & 0.318 & $* *$ \\
\hline More than degree & & & & 0.979 & 0.316 & $* * *$ & & & & 0.962 & 0.318 & $* * *$ \\
\hline None stated & & & & -0.317 & 0.203 & & & & & -0.323 & 0.204 & \\
\hline \multicolumn{13}{|c|}{ Tenure 1991 (reference = owners) } \\
\hline Social Renter & & & & -0.633 & 0.113 & $* * *$ & & & & -0.640 & 0.114 & $* * *$ \\
\hline Private Renter & & & & -0.669 & 0.176 & $* * *$ & & & & -0.656 & 0.179 & $* * *$ \\
\hline \multicolumn{13}{|c|}{ Change in health (reference $=$ no LLTI) } \\
\hline LLTI $91 \& 01$ & & & & -0.530 & 0.397 & & & & & -0.538 & 0.397 & \\
\hline LLTI 91 & & & & -0.010 & 0.289 & & & & & 0.002 & 0.285 & \\
\hline LLTI 01 & & & & -0.825 & 0.142 & $* * *$ & & & & -0.830 & 0.141 & $* * *$ \\
\hline Constant & 2.255 & 0.209 & & 3.212 & 0.314 & $* * *$ & 2.326 & 0.254 & $* * *$ & 3.197 & 0.347 & $* * *$ \\
\hline Initial Log Pseudo LL & & 45.941 & & & & & & & & & & \\
\hline Log Pseudo Likelihood & & 01.816 & & & 1629.250 & & & 002.017 & & & 614.122 & \\
\hline Wald & & 76.000 & & & 359.240 & & & 77.840 & & & 370.530 & \\
\hline Number of Observations & & 3,639 & & & 3,639 & & & 3,639 & & & 3,639 & \\
\hline
\end{tabular}

Source: Calculations done by the authors using data from the SLS. 
Table 3. Logistic regression of the probability of unemployment in 2001 for those employed in 1991

\begin{tabular}{|c|c|c|c|c|c|c|c|c|c|c|c|c|}
\hline & \multicolumn{6}{|c|}{ CATT level } & \multicolumn{6}{|c|}{ OA level } \\
\hline & \multicolumn{2}{|c|}{ Model 5} & & \multicolumn{2}{|c|}{ Model 6} & & \multicolumn{3}{|c|}{ Model 7} & \multicolumn{3}{|c|}{ Model 8} \\
\hline & Coef. & S.e. $^{\text {b }}$ & & Coef. & S.e. $^{\text {b }}$ & & Coef. & S.e. $^{\text {b }}$ & & Coef. & S.e. $^{\text {b }}$ & \\
\hline \multicolumn{13}{|c|}{ Neighbourhood level variables } \\
\hline \multicolumn{13}{|c|}{ Neighbourhood Unemployment 1991 (reference $=0-1.9 \%$ ) } \\
\hline $1.9-3.5 \%$ & 0.157 & 0.083 & * & 0.105 & 0.088 & & -0.002 & 0.081 & & -0.044 & 0.086 & \\
\hline $3.6-5.9 \%$ & 0.296 & 0.079 & $* * *$ & 0.135 & 0.084 & & 0.303 & 0.077 & $* * *$ & 0.166 & 0.082 & $* *$ \\
\hline $6.0-10.0 \%$ & 0.561 & 0.077 & $* * *$ & 0.320 & 0.084 & $* * *$ & 0.485 & 0.076 & $* * *$ & 0.249 & 0.082 & $* * *$ \\
\hline $10.1-54.9 \%$ & 0.915 & 0.076 & $* * *$ & 0.487 & 0.088 & $* * *$ & 0.889 & 0.074 & $* * *$ & 0.431 & 0.086 & $* * *$ \\
\hline \multicolumn{13}{|c|}{ Urban-rural classification 1991 (reference = Cities) } \\
\hline Urban Areas & & & & 0.066 & 0.061 & & & & & 0.057 & 0.060 & \\
\hline Small Towns & & & & 0.054 & 0.092 & & & & & 0.026 & 0.089 & \\
\hline Remote Towns & & & & 0.205 & 0.139 & & & & & 0.177 & 0.139 & \\
\hline Rural Areas & & & & 0.103 & 0.084 & & & & & 0.072 & 0.083 & \\
\hline Remote Areas & & & & 0.117 & 0.118 & & & & & 0.087 & 0.120 & \\
\hline \multicolumn{13}{|c|}{ Individual and Household level variables } \\
\hline Female (reference $=$ male) & & & & -0.618 & 0.054 & $* * *$ & & & & -0.617 & 0.054 & $* * *$ \\
\hline Ethnic (reference $=$ non et & nic) & & & 0.683 & 0.241 & $* * *$ & & & & 0.689 & 0.244 & $* * *$ \\
\hline Age in years (1991) & & & & 0.009 & 0.003 & $* * *$ & & & & 0.009 & 0.003 & $* * *$ \\
\hline \multicolumn{13}{|c|}{ Change in Household Type (reference = couple) } \\
\hline $91 \& 01$ Single & & & & 0.852 & 0.092 & $* * *$ & & & & 0.854 & 0.092 & $* * *$ \\
\hline 91 Single / 01 Couple & & & & -0.076 & 0.158 & & & & & -0.079 & 0.159 & \\
\hline 91 Couple / 01 Single & & & & 0.848 & 0.059 & $* * *$ & & & & 0.849 & 0.059 & $* * *$ \\
\hline \multicolumn{13}{|c|}{ Change in presence of children (reference $=$ children) } \\
\hline 91 / 01 No Children & & & & 0.193 & 0.068 & $* * *$ & & & & 0.190 & 0.070 & $* * *$ \\
\hline 91 No Child / 01 Child & & & & -0.078 & 0.093 & & & & & -0.075 & 0.093 & \\
\hline 91 Child / 01 No Child & & & & 0.143 & 0.073 & * & & & & 0.141 & 0.074 & * \\
\hline \multicolumn{13}{|c|}{ Qualifications 1991 (reference = none) } \\
\hline Less than degree & & & & -0.403 & 0.099 & $* * *$ & & & & -0.403 & 0.100 & $* * *$ \\
\hline More than degree & & & & -0.697 & 0.120 & $* * *$ & & & & -0.702 & 0.119 & $* * *$ \\
\hline None stated & & & & 0.157 & 0.152 & & & & & 0.157 & 0.151 & \\
\hline \multicolumn{13}{|c|}{ Tenure 1991 (reference = owners) } \\
\hline Social Renter & & & & 0.524 & 0.058 & $* * *$ & & & & 0.513 & 0.058 & $* * *$ \\
\hline Private Renter & & & & 0.355 & 0.101 & $* * *$ & & & & 0.343 & 0.102 & $* * *$ \\
\hline \multicolumn{13}{|c|}{ Change in health (reference $=$ no LLTI) } \\
\hline LLTI $91 \& 01$ & & & & 1.047 & 0.175 & $* * *$ & & & & 1.051 & 0.174 & $* * *$ \\
\hline LLTI 91 & & & & -0.321 & 0.289 & & & & & -0.320 & 0.288 & \\
\hline LLTI 01 & & & & 0.951 & 0.075 & $* * *$ & & & & 0.946 & 0.073 & $* * *$ \\
\hline Constant & -3.826 & 0.059 & $* * *$ & -4.381 & 0.140 & $* * *$ & -3.771 & 0.057 & $* * *$ & -4.316 & 0.138 & $* * *$ \\
\hline Initial Log Pseudo LL & & 678.380 & & & & & & & & & & \\
\hline Log Pseudo Likelihood & & 580.202 & & & 358.909 & & & 3573.306 & & & 358.936 & \\
\hline Wald & & 190.850 & & & 988.240 & & & 213.170 & & & 013.390 & \\
\hline Number of Observations & & 60,048 & & & 60,048 & & & 60,048 & & & 60,048 & \\
\hline
\end{tabular}

Source: Calculations done by the authors using data from the SLS. 
Table 4. CATT logistic regression for entering employment (Models 9-12) and loosing employment (Models 13-16), split by tenure.

\begin{tabular}{|c|c|c|c|c|c|c|c|c|c|c|c|c|c|c|c|c|c|c|c|c|c|c|c|c|}
\hline & \multicolumn{12}{|c|}{ Entering employment } & \multicolumn{12}{|c|}{ Losing employment } \\
\hline & \multicolumn{6}{|c|}{ Social Renters } & \multicolumn{6}{|c|}{ Owner Occupiers } & \multicolumn{6}{|c|}{ Social Renters } & \multicolumn{6}{|c|}{ Owner Occupiers } \\
\hline & \multicolumn{3}{|c|}{ Model 9} & \multicolumn{3}{|c|}{ Model 10} & \multicolumn{3}{|c|}{ Model 11} & \multicolumn{3}{|c|}{ Model 12} & \multicolumn{3}{|c|}{ Model 13} & \multicolumn{3}{|c|}{ Model 14} & \multicolumn{3}{|c|}{ Model 15} & \multicolumn{3}{|c|}{ Model 16} \\
\hline & Coef. & S.e. ${ }^{\mathrm{b}}$ & & Coef. & S.e. ${ }^{\mathrm{b}}$ & & Coef. & S.e. ${ }^{b}$ & & Coef. & S.e. ${ }^{\mathrm{b}}$ & & Coef. & S.e. & & Coef. & S.e. ${ }^{\mathrm{b}}$ & & Coef. & S.e. ${ }^{\mathrm{b}}$ & & Coef. & S.e. $^{\mathrm{b}}$ & \\
\hline \multicolumn{25}{|l|}{ Neighbourhood level } \\
\hline \multicolumn{25}{|c|}{ Neighbourhood Unemployment 1991 (reference $=0-1.88$ ) } \\
\hline $1.9-3.5 \%$ & -0.351 & 0.452 & & -0.517 & 0.438 & & 0.049 & 0.347 & & 0.050 & 0.382 & & -0.168 & 0.201 & & -0.203 & 0.210 & & 0.188 & 0.098 & * & 0.179 & 0.103 & * \\
\hline $3.6-5.9 \%$ & -0.198 & 0.434 & & -0.269 & 0.417 & & -0.656 & 0.303 & ** & -0.620 & 0.348 & * & 0.061 & 0.181 & & -0.017 & 0.197 & & 0.229 & 0.097 & $* * *$ & 0.167 & 0.102 & \\
\hline $6.0-10.0 \%$ & -0.493 & 0.421 & & -0.597 & 0.398 & & -0.895 & 0.299 & $* * *$ & -0.891 & 0.338 & $* * *$ & 0.319 & 0.167 & * & 0.274 & 0.182 & & 0.335 & 0.102 & $* * *$ & 0.283 & 0.107 & $* * *$ \\
\hline $10.1-54.9 \%$ & -0.623 & 0.415 & & -0.763 & 0.392 & * & -0.901 & 0.309 & $* * *$ & -0.749 & 0.347 & $* *$ & 0.476 & 0.162 & $* * *$ & 0.359 & 0.180 & $* *$ & 0.566 & 0.113 & $* * *$ & 0.491 & 0.122 & $* * *$ \\
\hline \multicolumn{25}{|c|}{ Urban-rural classification 1991 (reference $=$ Cities) } \\
\hline Urban Areas & & & & 0.003 & 0.127 & & & & & -0.166 & 0.222 & & & & & 0.073 & 0.097 & & & & & 0.060 & 0.083 & \\
\hline Small Towns & & & & -0.082 & 0.190 & & & & & 0.210 & 0.348 & & & & & -0.029 & 0.154 & & & & & 0.110 & 0.117 & \\
\hline Remote Towns & & & & 0.415 & 0.368 & & & & & 0.771 & 1.092 & & & & & 0.184 & 0.196 & & & & & 0.237 & 0.215 & \\
\hline Rural Areas & & & & 0.140 & 0.238 & & & & & -0.036 & 0.305 & & & & & 0.158 & 0.156 & & & & & 0.065 & 0.111 & \\
\hline Remote Areas & & & & -0.474 & 0.339 & & & & & -0.182 & 0.347 & & & & & 0.178 & 0.218 & & & & & 0.104 & 0.166 & \\
\hline Individual and Househo & ld level & variables & & & & & & & & & & & & & & & & & & & & & & \\
\hline Female (reference $=$ ma & & & & 0.676 & 0.241 & $* * *$ & & & & 1.232 & 0.403 & $* * *$ & & & & -1.202 & 0.147 & $* * *$ & & & & -0.671 & 0.114 & $* * *$ \\
\hline Ethnic (reference $=$ non & ethnic) & & & 1.588 & 0.852 & $*$ & & & & -0.871 & 0.611 & & & & & 0.098 & 0.749 & & & & & 0.882 & 0.262 & $* * *$ \\
\hline Age in years (1991) & & & & -0.014 & 0.007 & $*$ & & & & -0.002 & 0.011 & & & & & 0.009 & 0.005 & * & & & & 0.010 & 0.005 & $* *$ \\
\hline Change in Household $\mathrm{T}$ & ype (ref & rence $=$ & couple & & & & & & & & & & & & & & & & & & & & & \\
\hline 91 \& 01 Single & & & & -1.235 & 0.175 & $* * *$ & & & & -1.052 & 0.382 & $* * *$ & & & & 0.978 & 0.045 & $* * *$ & & & & 0.498 & 0.150 & $* * *$ \\
\hline 91 Single / 01 Couple & & & & 0.131 & 0.286 & & & & & 0.744 & 1.116 & & & & & 0.084 & -0.161 & & & & & -0.155 & 0.230 & \\
\hline 91 Couple / 01 Single & & & & -0.735 & 0.129 & $* * *$ & & & & -0.810 & 0.207 & $* * *$ & & & & 0.894 & -0.003 & $* * *$ & & & & 0.775 & 0.083 & $* * *$ \\
\hline Change in presence of $c$ & hildren & (referenc & $e=c h i$ & Iren) & & & & & & & & & & & & & & & & & & & & \\
\hline 91 / 01 No Children & & & & -0.314 & 0.153 & $* *$ & & & & -1.120 & 0.353 & $* * *$ & & & & 0.978 & 0.141 & $* * *$ & & & & 0.446 & 0.097 & $* * *$ \\
\hline 91 No Child / 01 Child & & & & 0.179 & 0.195 & & & & & -0.638 & 0.447 & & & & & 0.084 & 0.253 & & & & & 0.135 & 0.129 & \\
\hline 91 Child / 01 No Child & & & & 0.036 & 0.173 & & & & & -0.599 & 0.379 & & & & & 0.894 & 0.094 & $* * *$ & & & & 0.378 & 0.102 & $* * *$ \\
\hline Qualifications 1991 (ref & ference & none) & & & & & & & & & & & & & & & & & & & & & & \\
\hline Less than degree & & & & 0.959 & 0.583 & & & & & 0.571 & 0.506 & & & & & -0.511 & 0.265 & * & & & & -0.397 & 0.116 & *** \\
\hline More than degree & & & & 0.849 & 0.606 & & & & & 0.832 & 0.426 & * & & & & -0.245 & 0.367 & & & & & -0.758 & 0.138 & $* * *$ \\
\hline None stated & & & & -0.295 & 0.247 & & & & & -0.223 & 0.379 & & & & & 0.366 & 0.230 & & & & & -0.187 & 0.244 & \\
\hline Change in health (refere & ence $=\mathrm{n}$ & LLTI) & & & & & & & & & & & & & & & & & & & & & & \\
\hline LLTI $91 \& 01$ & & & & -0.452 & 0.446 & & & & & -1.058 & 0.863 & & & & & 1.029 & 0.260 & $* * *$ & & & & 1.122 & 0.244 & $* * *$ \\
\hline LLTI 91 & & & & -0.332 & 0.306 & & & & & - & - & & & & & -1.596 & 0.717 & $* *$ & & & & 0.428 & 0.313 & \\
\hline LLTI 01 & & & & -0.811 & 0.176 & $* * *$ & & & & -1.062 & 0.264 & $* * *$ & & & & 0.937 & 0.118 & $* * *$ & & & & 0.985 & 0.100 & $* * *$ \\
\hline Constant & 1.488 & 0.410 & $* * *$ & 2.236 & 0.489 & $* * *$ & 2.516 & 0.257 & $* * *$ & 3.165 & 0.574 & $* * *$ & -3.129 & 0.151 & $* * *$ & -3.140 & 0.287 & $* * *$ & -3.957 & 0.070 & $* * *$ & -4.401 & 0.223 & $* * *$ \\
\hline Log Pseudo LL & & 302.673 & & & 052.958 & & & -511.288 & & & -413.752 & & & 110.544 & & & 2542.160 & & & -4817 & & & 4261.940 & \\
\hline Wald & & 10.120 & & & 198.770 & & & 20.020 & & & 106.170 & & & 31.750 & & & 399.000 & & & 27.58 & & & 457.460 & \\
\hline Number of Obs. & & 1,992 & & & & & & 1,270 & & & & & & 14,833 & & & & & & 41,825 & & & & \\
\hline
\end{tabular}

Source: Calculations done by the authors using data from the SLS 